\title{
COMPORTAMENTO VOCAL DE CANTORES POPULARES
}

\author{
Vocal behavior of popular singers
}

\author{
Valquíria Zimmer ${ }^{(1)}$, Carla Aparecida Cielo ${ }^{(2)}$, Fernanda Mariotto Ferreira ${ }^{(3)}$
}

\section{RESUMO}

Objetivo: investigar aspectos do histórico, hábitos e comportamentos vocais de cantores populares, conforme o sexo e as categorias profissional e amador. Método: entrevista com 47 cantores, 25 homens e 22 mulheres. Resultados: significância estatística nos seguintes achados: MASCULINO - microfone nos ensaios, ausência de problemas vocais diagnosticados, ausência de orientações sobre higiene vocal, dor ou desconforto após cantar, ausência de alergias e problemas respiratórios; FEMININO - aulas de canto e conhecimento sobre postura; AMADOR - não cantar dançando, não imitar vozes, ausência de avaliação otorrinolaringológica, ausência de problemas vocais diagnosticados, ausência de terapia fonoaudiológica, ausência de orientações de anatomofisiologia vocal e não utilização de álcool nos ensaios; PROFISSIONAL - rouquidão, conhecimento sobre articulação, álcool durante os shows, "garganta suja" ou pigarro, dor após cantar. Conclusões: a comparação entre os sexos evidenciou que os homens utilizavam microfone no ensaio, não apresentavam problemas alérgicos ou respiratórios, nem problemas vocais diagnosticados, mas apresentavam sensação de dor ou desconforto após o canto e não possuíam noções sobre higiene vocal; e que as mulheres realizavam aulas de canto e possuíam orientações de postura. A comparação entre amadores e profissionais mostrou que os amadores não cantavam dançando, não imitavam vozes, não utilizavam álcool nos ensaios, e não apresentavam problemas vocais diagnosticados, mas não possuíam avaliação otorrinolaringológica, não realizavam terapia fonoaudiológica, e não possuíam conhecimento sobre anatomofisiologia vocal; e os profissionais apresentavam queixa de rouquidão, de "garganta suja" ou pigarro e de dor após cantar, e usavam álcool durante os shows, apesar de possuir conhecimento sobre articulação.

DESCRITORES: Voz; Qualidade da Voz; Fonoaudiologia; Música; Perfil de Saúde; Distúrbios da Voz

\section{INTRODUÇÃO}

A voz é o meio mais natural e antigo que possibilita a produção musical, uma vez que ao nascer é ela que determina a capacidade de produzir melodia. A laringe é, portanto, o instrumento musical mais primitivo de que se tem conhecimento ${ }^{1,2}$.

A capacidade de cantar é muito variável entre a população em geral. Algumas pessoas são

(1) Fonoaudióloga clínica; Mestranda em Distúrbios da Comunicação Humana na Universidade Federal de Santa Maria - RS.

(2) Fonoaudióloga; Professor Adjunto de Graduação e PósGraduação do Departamento de Fonoaudiologia da Universidade Federal de Santa Maria - RS; Doutora em Lingüística Aplicada pela Pontifícia Universidade Católica do Rio Grande do Sul.

(3) Fonoaudióloga; Especialização com ênfase em Voz pelo Instituto Porto Alegre da Igreja Metodista.

Conflito de interesses: inexistente capazes de produzir um som melodioso com facilidade, enquanto outras encontram grande dificuldade em realizar uma boa melodia. É provável que os indivíduos que cantam com melodia possuam habilidades inerentes e ou tenham adquirido a habilidade com o treinamento de sua voz ${ }^{3,4}$.

A voz possui características individuais e, portanto deve ser classificada de acordo com os padrões que a determinam. Entre as variáveis, encontram-se o fator biológico inerente ao sexo, masculino e feminino, e o fator da idade como cruciais no momento da classificação vocal ${ }^{5}$. A literatura aponta outros critérios que devem ser considerados, como as características anatômicas da laringe, a estrutura corporal, os aspectos funcionais da emissão e a própria personalidade do individuo².

Para o cantor, a voz é sua maneira de expressar os sentimentos e sua válvula de escape emocional, além de ser uma função intelectual e artística onde 
seu corpo e sua voz estão integrados na intenção de interpretar uma canção6-8.

A voz falada e a voz cantada têm realidades diferentes. A voz falada é em geral natural e inconsciente, e não necessita de ajustes ou treinamentos prévios, nela está a representação do pensamento, sua melodia e ritmo estão na entonação. Já a voz cantada, é em geral consciente, exige aprimoramento e adaptações prévias, devido às necessidades do canto, e nela está a representação artística da emoção, 9,10.

O canto popular é considerado o estilo mais espontâneo, sem regras precisas de sonoridade, no qual as palavras e a articulação assumem papel de grande importância 9 .

O indivíduo que utiliza a voz como instrumento de trabalho é considerado um profissional da voz, e este depende de certa produção e/ou qualidade vocal específica para sua sobrevivência profissional, como, por exemplo, os telefonistas, professores, locutores, sacerdotes, advogados, vendedores e cantores. Para estes profissionais a função vocal assume o papel de meio de sobrevivência, já que depende dela o bom desempenho de sua atividade profissional ${ }^{9,11}$.

O canto amador diferencia-se do canto profissional. O cantor profissional realiza shows e apresentações constantemente, obtêm seu sustento por meio da música, e procuram fama e reconhecimento do público e dos fãs, enquanto o cantor amador não possui essa rotina, cantando pelo prazer, sendo que demonstra amor pela música, acredita que cantar vai Ihe proporcionar companhia, aventura e muitas vezes aceitação em meio à sociedade ${ }^{12}$.

Por ser seu instrumento de trabalho, o profissional da voz cantada deve cuidar muito bem de seu aparelho fonador, estando atento a ele em todas as situações. A adequada emissão vocal depende do bom funcionamento do organismo do cantor, sendo que a voz produzida na laringe faz parte do corpo humano e os cuidados com ela devem ser considerados como cuidados com a saúde, daí o termo saúde vocal ${ }^{9,10,13}$.

Os cantores, assim como os demais profissionais da voz, deveriam ter clareza dos princípios que englobam a saúde vocal. Estes conceitos são importantes para prevenir irritações e desgaste das pregas vocais, evitando alterações que podem impossibilitar o exercício da profissão ${ }^{13-15}$.

O objetivo deste trabalho foi investigar os aspectos do histórico, dos hábitos e dos comportamentos vocais de cantores adultos, conforme o sexo e as categorias de profissional e amador.

\section{MÉTODO}

Esta pesquisa caracteriza-se como transversal, quantitativa e exploratória, por meio de entrevista, visando à população de cantores.

Para a composição da amostra deste estudo, foram estabelecidos critérios de inclusão e de exclusão, além da leitura e assinatura do Termo de Consentimento Livre e Esclarecido (TCLE).

Os critérios de inclusão considerados foram: a forma de expressão musical, ou seja, o canto popular; os cantores deveriam estar no último ano da faixa de adolescência (19 anos), na faixa etária adulta, e até os 60 anos da faixa etária de meia-idade (DeCS, 2010), pois, se acredita que nessas faixas etárias o aparelho fonador ainda não sofreu tanto a influência das alterações estruturais do envelhecimento como também não sofre mais as alterações do período da muda vocal ${ }^{16}$ concordância e assinatura do TCLE.

Os critérios de exclusão constituíram-se da não utilização da expressão cantada lírica ou coral; menores de 19 anos e maiores de 60 anos de idade; desinteresse em participar da pesquisa.

A verificação dos critérios de inclusão e de exclusão foi realizada por meio da aplicação de questionário, elaborado com base na literatura 9,17-19 com perguntas abertas e fechadas sobre os dados de identificação, sexo, idade, tipo de canto, categoria profissional ou amadora.

Desta forma, a amostra desta pesquisa constituiu-se de 47 cantores populares voluntários, 22 amadores e 25 profissionais, 25 homens e 22 mulheres, com idades entre 18 e 60 anos, com média de idade feminina de 26, 82 anos e média masculina 28, 96 anos. Foram excluídos três sujeitos por não se enquadrarem nos critérios de inclusão devido à utilização da expressão canto coral.

A coleta de dados foi realizada com os 47 sujeitos por meio do mesmo questionário utilizado para a amostragem ${ }^{9}$ 17-19, que continha perguntas abertas e fechadas, com base na literatura ${ }^{1,6,9,13,15,18,19}$, referentes à atividade vocal profissional e não-profissional do mesmo, e de outros fatores relevantes que pudessem influenciar seu desempenho vocal como: status da carreira (profissional ou amador); utilização de microfone durante os ensaios e durante os shows; imitação de vozes; avaliação otorrinolaringológica; queixa de rouquidão frequente; problema de voz diagnosticado; participação em aulas de canto (no passado e atualmente); terapia fonoaudiológica; realização de aquecimento vocal; orientações quanto à respiração, postura durante o canto, higiene vocal, anatomia e fisiologia vocal e articulação; hábitos vocais durante os ensaios e 
durante os shows quanto ao uso de álcool, maconha, cocaína, cigarros, medicamentos e ingestão de água; sensações de "garganta suja", pigarro, dor ou desconforto após cantar; uso de alguma substância para melhorar a voz; e relato de problemas de saúde relacionados a fatores alérgico, cardíaco, circulatório, hormonal, neurológico, respiratório e otorrinolaringológico.

Este trabalho foi implementado após a aprovação do Comitê de Ética em Pesquisa da instituição de origem, sob o protocolo de número 23081. 008439/2007-16.

Na comparação das variáveis categóricas entre grupos foram utilizados o teste Qui-Quadrado e o teste exato de Fisher. O nível de significância adotado para os testes estatísticos foi de $5 \%$, ou seja, $p<0.05$. Para análise estatística foi utilizado o programa computacional The SAS System for Windows (Statistical Analysis System), versão 8.02. SAS Institute Inc., 1999-2001, Cary, NC, USA.

\section{RESULTADOS}

$\mathrm{Na}$ Tabela 1, são expostos os resultados da comparação entre as variáveis por sexo.

$\mathrm{Na}$ Tabela 2, são expostos os resultados da comparação entre as variáveis por categoria de canto amador e profissional.

\section{DISCUSSÃO}

Quanto à utilização de microfone durante os ensaios, houve significância a favor do sexo masculino quando comparado ao sexo feminino, sendo que, durante os shows, ambos os sexos o utilizavam.

Os recursos de amplificação vocal são diversos e, dentre eles, destacam-se o uso de microfone, do retorno, e o controle de pitch. O uso desses equipamentos de amplificação da voz é muito importante tanto durante os shows como durante os ensaios. São esses recursos que favorecem o enriquecimento e a qualidade vocal do cantor ${ }^{9,13}$ e auxiliam a evitar excessos de intensidade vocal ${ }^{20,21}$.

Apesar do efeito benéfico do uso do microfone, afirma-se que os cantores populares, justamente por fazerem uso desse recurso de amplificação da voz, não demonstram tanta preocupação em desenvolver técnicas específicas de produção vocal ${ }^{13}$.

Entre os homens, verificou-se ausência significante de diagnóstico de problemas de voz, quando comparados às cantoras. A literatura traz referências ao sexo feminino como o mais predisposto a distúrbios vocais ${ }^{20,22}$.

Em um estudo longitudinal com estudantes de canto foram registradas semestralmente as características vocais durante os ensaios. Observaram-se efeitos significantes sobre a voz cantada, principalmente quanto ao aumento da faixa de frequências e intensidade máxima, afirmando que o treinamento de técnicas vocais no estudo do canto traz benefícios aos indivíduos que o praticam ${ }^{23}$. Assim, a prática do canto pode ser considerada benéfica ao aparato vocal, reforçando o fato dos homens cantores não apresentarem problemas de voz.

Pesquisa sobre as condições vocais de vendedores de móveis e eletrodomésticos verificou que todos os sujeitos que mencionaram alguma alteração vocal eram do sexo feminino ${ }^{20}$.

Estudo refere que os sintomas vocais como o cansaço ao falar, perda da voz e voz fraca, são mais presentes entre as mulheres. As explicações para estas queixas seriam as mudanças hormonais mais frequentes no decorrer de suas vidas e a própria predisposição a alterações de voz, maior nesse gênero, por conta da configuração laríngea específica e do ácido hialurônico. A lâmina própria diferencia-se entre os homens e as mulheres e a quantia deste ácido é menor no sexo feminino, o que predispõe esta população a lesões como os nódulos vocais ${ }^{21}$.

A presente pesquisa mostrou resultados significantes quanto à participação do sexo feminino em aulas de canto, quando comparado ao sexo masculino.

Estudo sobre o perfil vocal de regentes de coral da cidade de São Paulo/SP reforça que a prática de aulas de canto é definida na literatura como um aprimoramento importante para cantores e regentes de coral sendo que deveria fazer parte do cotidiano destes profissionais ao longo de suas vidas ${ }^{19,24}$.

Pesquisas mostram que as aulas de canto proporcionam desenvolvimento de todo mecanismo vocal resultando em melhor qualidade de voz cantada sem esforço, melhora no controle da passagem e da intensidade da $\operatorname{voz}^{19,24}$.

A extensão vocal pode ser ampliada com o auxilio de um treinamento vocal adequado. Pesquisadores afirmam que é possível modificar as configurações anatômicas do trato vocal. Alguns indivíduos mesmo tendo uma voz considerada boa para o canto ela poderá ter extensão curta e, portanto, condições restritas de variar entre sons agudos e graves ${ }^{12}$.

Segundo estudo que investigou os efeitos sobre a extensão vocal de um coral amador evangélico, o ato de cantar constitui-se em um ótimo exercício para o desenvolvimento do aparelho respiratório e auditivo ${ }^{12}$.

Afirma-se, ainda, que cantar traz efeitos benéficos para indivíduos disfônicos ${ }^{12}$. Em estudo 
Tabela 1 - Comparação das variáveis categóricas entre o sexo dos cantores

\begin{tabular}{|c|c|c|c|c|c|c|c|c|c|}
\hline \multirow{3}{*}{$\begin{array}{l}\text { SEXO } \\
\text { ITENS }\end{array}$} & \multicolumn{4}{|c|}{ FEMININO } & \multicolumn{4}{|c|}{ MASCULINO } & \multirow{3}{*}{ VALOR - $p^{*}$} \\
\hline & \multicolumn{2}{|c|}{ NÃO } & \multicolumn{2}{|c|}{ SIM } & \multicolumn{2}{|c|}{ NÃO } & \multicolumn{2}{|c|}{ SIM } & \\
\hline & $\mathrm{n}$ & $\%$ & $n$ & $\%$ & $n$ & $\%$ & $n$ & $\%$ & \\
\hline Status atual da carreira (profissional) & 10 & 45,45 & 12 & 54,55 & 12 & 48,00 & 13 & 52,00 & 0,862 \\
\hline Utiliza microfone no show & 0 & 00,00 & 22 & 100,0 & 0 & 00,00 & 25 & 100,0 & - \\
\hline Utiliza microfone no ensaio & 9 & 50,00 & 9 & 50,00 & 3 & 15,79 & 16 & 84,21 & $0,026^{*}$ \\
\hline Canta em pé & 3 & 13,64 & 19 & 86,36 & 3 & 12,00 & 22 & 88,00 & 1,000 \\
\hline Canta sentado & 13 & 59,09 & 9 & 40,91 & 17 & 68,00 & 8 & 32,00 & 0,526 \\
\hline Canta caminhando & 21 & 95,45 & 1 & 04,55 & 22 & 88,00 & 3 & 12,00 & 0,612 \\
\hline Canta dançando & 20 & 90,91 & 2 & 9,09 & 20 & 80,00 & 5 & 20,00 & 0,423 \\
\hline Imita vozes & 17 & 77,27 & 5 & 22,73 & 14 & 56,00 & 11 & 44,00 & 0,125 \\
\hline Possui avaliação otorrinolaringológica & 13 & 65,00 & 7 & 35,00 & 14 & 58,33 & 10 & 41,67 & 0,651 \\
\hline Fica/ficou rouco com frequência & 7 & 31,82 & 15 & 68,18 & 10 & 40,00 & 15 & 60,00 & 0,560 \\
\hline Problema de voz diagnosticado & 15 & 71,43 & 6 & 28,57 & 24 & 96,00 & 1 & 4,00 & $0,037^{*}$ \\
\hline Fez aula de canto & 2 & 9,09 & 20 & 90,91 & 9 & 36,00 & 16 & 64,00 & $0,030^{*}$ \\
\hline Fez terapia fonoaudiológica & 16 & 72,73 & 6 & 27,27 & 17 & 68,00 & 8 & 32,00 & 0,724 \\
\hline Faz aula de canto atualmente & 12 & 54,55 & 10 & 45,45 & 19 & 76,00 & 6 & 24,00 & 0,121 \\
\hline Aquecimento vocal & 16 & 72,73 & 6 & 27,27 & 18 & 72,00 & 7 & 28,00 & 0,956 \\
\hline Recebeu orientação sobre respiração & 1 & 4,55 & 21 & 95,45 & 7 & 28,00 & 18 & 72,00 & 0,052 \\
\hline Recebeu orientação sobre postura durante o canto & 3 & 13,64 & 19 & 86,36 & 10 & 40,00 & 15 & 60,00 & $0,044^{*}$ \\
\hline Recebeu orientação sobre higiene vocal & 7 & 31,82 & 15 & 68,18 & 16 & 64,00 & 9 & 36,00 & $0,028^{*}$ \\
\hline Recebeu orientação sobre anatomia e fisiologia da voz & 11 & 50,00 & 11 & 50,00 & 18 & 72,00 & 7 & 28,00 & 0,122 \\
\hline Recebeu orientação sobre articulação & 8 & 36.36 & 14 & 63,64 & 15 & 60,00 & 10 & 40,00 & 0,106 \\
\hline Uso de álcool no ensaio & 15 & 78,95 & 4 & 21,05 & 18 & 72,00 & 7 & 28,00 & 0,732 \\
\hline Uso de álcool no show & 11 & 61,11 & 7 & 38,89 & 11 & 44,00 & 14 & 56,00 & 0,268 \\
\hline Uso de maconha no ensaio & 13 & 81,25 & 3 & 18,75 & 20 & 100,0 & 0 & 00,00 & 0,078 \\
\hline Uso de maconha no show & 13 & 81,25 & 3 & 18,75 & 18 & 100,0 & 0 & 00,00 & 0,094 \\
\hline Uso de cocaína no ensaio & 22 & 100,0 & 0 & 00,00 & 25 & 100,0 & 0 & 00,00 & - \\
\hline Uso de cocaína no show & 22 & 100,0 & 0 & 00,00 & 25 & 100,0 & 0 & 00,00 & - \\
\hline Uso de cigarro no ensaio & 14 & 82,35 & 3 & 17,65 & 17 & 85,00 & 3 & 15,00 & 1,000 \\
\hline Uso de cigarro no show & 12 & 70,59 & 5 & 29,41 & 14 & 77,78 & 4 & 22,22 & 0,711 \\
\hline Uso de medicamentos no ensaio & 11 & 78,57 & 3 & 21,43 & 13 & 100,0 & 0 & 0,00 & 0,222 \\
\hline Uso de medicamentos no show & 10 & 76,92 & 3 & 23,08 & 9 & 81,82 & 2 & 18,18 & 1,000 \\
\hline Uso de água no ensaio & 4 & 21,05 & 15 & 78,95 & 2 & 9,09 & 20 & 90,91 & 0,390 \\
\hline Uso de água no show & 3 & 15,79 & 16 & 84,21 & 1 & 4,76 & 20 & 95,24 & 0,331 \\
\hline Sensação de "garganta suja" ou pigarro & 8 & 38,1 & 13 & 61,90 & 9 & 36,00 & 16 & 64,00 & 0,883 \\
\hline Dor ou desconforto depois de cantar & 10 & 50 & 10 & 50,00 & 3 & 13,64 & 19 & 86,36 & $0,011^{*}$ \\
\hline Faz uso de alguma substância para melhorar a voz & 16 & 76,19 & 5 & 23,81 & 12 & 50,00 & 12 & 50,00 & 0,071 \\
\hline Relato de problema alérgico & 7 & 31,82 & 15 & 68,18 & 21 & 84,00 & 4 & 16,00 & $0,001^{*}$ \\
\hline Relato de problema cardíaco & 22 & 100,0 & 0 & 00,00 & 25 & 100,0 & 0 & 00,00 & - \\
\hline Relato de problema circulatório & 22 & 100,0 & 0 & 00,00 & 25 & 100,0 & 0 & 00,00 & - \\
\hline Relato de problema hormonal & 22 & 100 & 0 & 00,00 & 22 & 88,00 & 3 & 12,00 & 0,237 \\
\hline Relato de problema neurológico & 22 & 100,0 & 0 & 00,00 & 25 & 100,0 & 0 & 00,00 & - \\
\hline Relato de problema respiratório & 16 & 72,73 & 6 & 27,27 & 24 & 96 & 1 & 04,00 & $0,040^{*}$ \\
\hline Relato de problema otorrinolaringológico & 20 & 90,91 & 2 & 09,09 & 24 & 96 & 1 & 04,00 & 0,593 \\
\hline
\end{tabular}

*Significância estatística pelo Teste Exato de Fisher e Teste Qui-Quadrado

realizado com indivíduos normais e com alterações vocais, os exercícios de voz melhoraram o controle da resistência glótica dos sujeitos disfônicos ${ }^{25}$.

Em pesquisa realizada com um coral amador a apresentação dos resultados das medidas do tempo máximo de fonação e do perfil de extensão vocal permitiu confirmar que houve melhora no desempenho geral de um grupo de cantores ainda que não profissionais, após o ensaio coral e o exercício vocal ${ }^{12}$.
No item sobre a orientação de postura durante o canto, os resultados mostram significância para o sexo feminino, quando comparado ao sexo masculino, o que pode estar relacionado à maior busca de aulas de canto pelas mulheres.

$\mathrm{Na}$ produção da voz, observa-se a necessidade de harmonia entre fatores psicológicos e físicos sendo, portanto, muito importante a postura corporal. Durante o canto, recomenda-se que o cantor permaneça em postura firme, apoiado 
Tabela 2 - Comparação entre as variáveis por categoria de canto amador e profissional

\begin{tabular}{|c|c|c|c|c|c|c|c|c|c|}
\hline \multirow{3}{*}{$\begin{array}{l}\text { CATEGORIA } \\
\text { ITENS }\end{array}$} & \multicolumn{4}{|c|}{ AMADOR } & \multicolumn{4}{|c|}{ PROFISSIONAL } & \multirow{3}{*}{ VALOR $-\mathbf{p}^{*}$} \\
\hline & \multicolumn{2}{|c|}{ NÃO } & \multicolumn{2}{|c|}{ SIM } & \multicolumn{2}{|c|}{ NÃO } & \multicolumn{2}{|c|}{ SIM } & \\
\hline & $\mathbf{n}$ & $\%$ & $\mathrm{n}$ & $\%$ & $\mathbf{n}$ & $\%$ & $\mathbf{n}$ & $\%$ & \\
\hline Utiliza microfone no show & 0 & 00,00 & 22 & 100,0 & 0 & 00,00 & 25 & 100,0 & - \\
\hline Utiliza microfone no ensaio & 7 & 43,75 & 9 & 56,25 & 5 & 23,81 & 16 & 76,19 & 0,199 \\
\hline Canta em pé & 4 & 18,18 & 18 & 81,82 & 2 & 8,00 & 23 & 92,00 & 0,398 \\
\hline Canta sentado & 12 & 54,55 & 10 & 45,45 & 18 & 72,00 & 7 & 28,00 & 0,214 \\
\hline Canta caminhando & 20 & 90,91 & 2 & 9,09 & 23 & 92,00 & 2 & 8,00 & 1,000 \\
\hline Canta dançando & 22 & 100,0 & 0 & 0,00 & 18 & 72,00 & 7 & 28,00 & $0,010^{*}$ \\
\hline Imita vozes & 18 & 81,82 & 4 & 18,18 & 13 & 52,00 & 12 & 48,00 & $0,031^{*}$ \\
\hline Possui avaliação otorrinolaringológica & 18 & 85,71 & 3 & 14,29 & 9 & 39,13 & 14 & 60,87 & $0,002^{*}$ \\
\hline Fica/ficou rouco com frequência & 13 & 59,09 & 9 & 40,91 & 4 & 16,00 & 21 & 84,00 & $0,002^{*}$ \\
\hline Problema de voz diagnosticado & 21 & 100,0 & 0 & 0,00 & 18 & 72,00 & 7 & 28,00 & $0,011^{*}$ \\
\hline Fez aula de canto & 7 & 31,82 & 15 & 68,18 & 4 & 16,00 & 21 & 84,00 & 0,201 \\
\hline Fez terapia fonoaudiológica & 20 & 90,91 & 2 & 9,09 & 13 & 52,00 & 12 & 48,00 & $0,004^{*}$ \\
\hline Faz aula de canto atualmente & 15 & 68,18 & 7 & 31,82 & 16 & 64,00 & 9 & 36,00 & 0,763 \\
\hline Aquecimento vocal & 18 & 81,82 & 4 & 18,18 & 16 & 64,00 & 9 & 36,00 & 0,173 \\
\hline Recebeu orientação sobre respiração & 6 & 27,27 & 16 & 72,73 & 2 & 8,00 & 23 & 92,00 & 0,123 \\
\hline Recebeu orientação sobre postura durante o canto & 9 & 40,91 & 13 & 59,09 & 4 & 16,00 & 21 & 84,00 & 0,057 \\
\hline Recebeu orientação sobre higiene vocal & 14 & 63,64 & 8 & 36,36 & 9 & 36,00 & 16 & 64,00 & 0,059 \\
\hline Recebeu orientação sobre anatomia e fisiologia da voz & 17 & 77,27 & 5 & 22,73 & 12 & 48,00 & 13 & 52,00 & $0,039^{*}$ \\
\hline Recebeu orientação sobre articulação & 15 & 68,18 & 7 & 31,82 & 8 & 32,00 & 17 & 68,00 & $0,013^{*}$ \\
\hline Uso de álcool no ensaio & 18 & 90,00 & 2 & 10,00 & 15 & 62,50 & 9 & 37,50 & $0,036^{*}$ \\
\hline Uso de álcool no show & 13 & 68,42 & 6 & 31,58 & 9 & 37,50 & 15 & 62,50 & $0,044^{*}$ \\
\hline Uso de maconha no ensaio & 16 & 100,0 & 0 & 0,00 & 17 & 85,00 & 3 & 15,00 & 0,238 \\
\hline Uso de maconha no show & 14 & 100,0 & 0 & 0,00 & 17 & 85,00 & 3 & 15,00 & 0,251 \\
\hline Uso de cocaína no ensaio & 22 & 100,0 & 0 & 00,00 & 25 & 100,0 & 0 & 00,00 & - \\
\hline Uso de cocaína no show & 22 & 100,0 & 0 & 00,00 & 25 & 100,0 & 0 & 00,00 & - \\
\hline Uso de cigarro no ensaio & 16 & 94,12 & 1 & 5,88 & 15 & 75,00 & 5 & 25,00 & 0,189 \\
\hline Uso de cigarro no show & 13 & 86,67 & 2 & 13,33 & 13 & 65,00 & 7 & 35,00 & 0,244 \\
\hline Uso de medicamentos no ensaio & 13 & 86,67 & 2 & 13,33 & 11 & 91,67 & 1 & 8,33 & 1,000 \\
\hline Uso de medicamentos no show & 10 & 76,92 & 3 & 23,08 & 9 & 81,82 & 2 & 18,18 & 1,000 \\
\hline Uso de água no ensaio & 4 & 23,53 & 13 & 76,47 & 2 & 8,33 & 22 & 91,67 & 0,212 \\
\hline Uso de água no show & 2 & 11,76 & 15 & 88,24 & 2 & 8,70 & 21 & 91,30 & 1,000 \\
\hline Sensação de "garganta suja" ou pigarro & 12 & 57,14 & 9 & 42,86 & 5 & 20,00 & 20 & 80,00 & $0,009^{*}$ \\
\hline Dor ou desconforto depois de cantar & 9 & 52,94 & 8 & 47,06 & 4 & 16,00 & 21 & 84,00 & $0,011^{*}$ \\
\hline Faz uso de alguma substância para melhorar a voz & 16 & 76,19 & 5 & 23,81 & 12 & 50,00 & 12 & 50,00 & 0,071 \\
\hline Relato de problema alérgico & 15 & 68,18 & 7 & 31,82 & 13 & 52,00 & 12 & 48,00 & 0,259 \\
\hline Relato de problema cardíaco & 22 & 100,0 & 0 & 00,00 & 25 & 100,0 & 0 & 00,00 & - \\
\hline Relato de problema circulatório & 22 & 100,0 & 0 & 00,00 & 25 & 100,0 & 0 & 00,00 & - \\
\hline Relato de problema hormonal & 21 & 95,45 & 1 & 4,55 & 23 & 92,00 & 2 & 8,00 & 1,000 \\
\hline Relato de problema neurológico & 22 & 100,0 & 0 & 00,00 & 25 & 100,0 & 0 & 00,00 & - \\
\hline Relato de problema respiratório & 20 & 90,91 & 2 & 9,09 & 20 & 80,00 & 5 & 20,00 & 0,423 \\
\hline Relato de problema otorrinolaringológico & 21 & 95,45 & 1 & 4,55 & 23 & 92,00 & 2 & 8,00 & 1,000 \\
\hline
\end{tabular}

*Significância estatística pelo Teste Exato de Fisher e Teste Qui-Quadrado

sobre os dois pés, porém flexível, permitindo os movimentos ${ }^{26}$.

Refere-se que é importante manter a atenção a algumas regiões do corpo, entre elas a cabeça, o pescoço, os ombros e o tórax, pois são essenciais para a produção vocal, agindo diretamente sobre as estruturas relacionadas ao canto como as pregas vocais, a laringe, as cavidades de ressonância e a função da respiração ${ }^{26}$.

A postura pode influenciar o comportamento vocal do individuo e os desvios posturais podem contribuir com os distúrbios da voz e potencializar patologias vocais como fendas glóticas, nódulos, entre outras ${ }^{10,26}$.

Os cantores do sexo masculino apresentaram resultados significantes quanto ao desconhecimento sobre higiene vocal, comparativamente ao sexo feminino. Observa-se, assim, maior preocupação do sexo feminino quanto à procura de aulas de canto e de orientações desde os princípios básicos de saúde vocal como também quanto à postura correta durante o canto.

Estudo sobre os hábitos vocais, questões de saúde e sintomas vocais de vendedores de móveis 
e eletrodomésticos contou com amostra com maior número de homens que percebiam a presença de sintomas vocais, mas não os relacionavam às alterações de voz ${ }^{20}$.

Neste trabalho, houve significância estatística para o relato masculino, em comparação ao feminino, de sensações de dor ou desconforto depois de cantar, o que pode também estar relacionado ao fato dos sujeitos não apresentarem noções de saúde vocal e não realizarem aulas de canto.

Estudo sobre sintomas vocais e suas prováveis causas revelam dados divergentes dos resultados encontrados nesta pesquisa, sendo que os autores verificaram maior número de queixas vocais como rouquidão, dor de garganta, pigarro e ardor na garganta no sexo feminino ${ }^{21}$.

Apesar do relato masculino significante de sensações de dor ou desconforto depois de cantar, nos itens que abordavam o relato de problemas de saúde, os cantores do sexo masculino, quando comparados ao sexo feminino, apresentaram resultados significantes quanto à ausência de alergia e de problemas respiratórios que poderiam estar relacionados a essas sensações.

Os problemas alérgicos e respiratórios são prejudiciais à projeção vocal|27, aspecto essencial ao profissional do canto.

A literatura afirma que os distúrbios alérgicos e nasais, além de aumentar a irritabilidade do trato vocal, prejudicam a ressonância vocal, a mucosa respiratória fica edemaciada dificultando a vibração das pregas vocais, e ocorre a obstrução das vias aéreas superiores ${ }^{\text {9, 13, 28, } 29}$.

Quanto às doenças respiratórias, podem comprometer a função aérea e provocar efeito direto sobre a fala e sobre a voz (intensidade, altura, qualidade) $)^{27}$.

Em relação às categorias de canto amador e de canto profissional, observou-se que foi significante não cantar dançando entre os cantores amadores, quando comparados aos profissionais.

O ato de cantar é uma ação que exige grande demanda de energia física e controle das emoções ${ }^{26}$. Acredita-se que cantar dançando exige maior fôlego do indivíduo e, portanto a ausência significativa de dança durante o canto para a categoria amadora poderia ser compreendida pelo desgaste e ou desconforto físico, além do menor nível de treinamento que a categoria profissional apresenta.

É preciso realizar um preparo quanto à expressividade corporal durante o canto. Quando o canto é praticado em forte intensidade e em notas agudas, certos ajustes do trato vocal tornam-se necessários ${ }^{30} \mathrm{e}$, se estiver associado à movimentação corporal, constitui-se em sobrecarga muscular, semelhante àquela realizada por atletas ${ }^{26}$.

Verificou-se que a imitação de vozes foi significantemente ausente na categoria de canto amador comparada ao canto profissional.

Acredita-se que o cantor amador não precise imitar vozes, pois não tem a necessidade de agradar a um público e sua carreira profissional não depende do canto ou da imitação, mas, em cantores populares que utilizam a voz profissionalmente, no início da carreira e na busca de sucesso, é comum observar a imitação da voz de ídolos. Todavia, a imitação de vozes pode acarretar ajustes fonatórios inadequados e, portanto, abusos vocais ${ }^{9}$.

$\mathrm{Na}$ categoria amador, foi significante o número de cantores com ausência de avaliação otorrinolaringológica, em comparação com a categoria profissional.

Acredita-se que a categoria amadora não expressa a atenção que deveria quanto à realização de avaliação otorrinolaringológica. É possível que os cantores amadores procurem menos a avaliação médica devido à menor ocorrência de queixas vocais (que foi significante na categoria profissional) e também por utilizarem a voz para o canto esporadicamente.

A avaliação otorrinolaringológica é de grande importância para o diagnóstico de alguma lesão em prega vocal que possa comprometer a saúde vocal, bem como prejudicar a qualidade da voz no momento das apresentações ${ }^{31}$. Existe, ainda, o preocupante fator negativo que afetará a longevidade da voz do cantor, caso ele prossiga a cantar na presença de lesão laríngea não diagnosticada ${ }^{5,16}$.

Patologias como nódulos e edema de Reinke podem se configurar como resultantes de mau uso e abuso da voz associados à falta de cuidados básicos para manter a saúde vocal e, quando há a possibilidade de realização de exames de imagem, são essas as alterações vocais mais encontradas nestes profissionais ${ }^{15}, 32,33$.

Um estudo sobre a análise comparativa entre avaliação fonoaudiológica perceptivo-auditiva, análise acústica e laringoscopias indiretas, para avaliação vocal em população com queixa vocal, apresentou resultados de concordância entre os achados da avaliação vocal perceptivo-auditiva e as avaliações médicas, evidenciando a capacidade de detecção de problemas vocais e laríngeos das mesmas $^{34}$.

$\mathrm{Na}$ categoria profissional comparativamente à categoria de canto amador, houve significância estatística quanto à queixa de rouquidão frequente, dor após cantar, "garganta suja" e pigarro. Quadros de disfonia por abuso vocal, uso inadequado da 
voz ou associados às alterações de vias aéreas superiores podem estar relacionados à queixa de rouquidão ${ }^{17}$. Provavelmente, por utilizar a voz por longo período na realização de shows, o profissional tende a realizar mais usos vocais incorretos e ou abusivos e, portanto, referir maior número de queixas do que o cantor da categoria amador que utiliza o canto esporadicamente.

Pesquisa sobre os sintomas vocais e suas prováveis causas encontrou relação estatisticamente significante entre a presença de rouquidão e o uso intenso da voz ${ }^{21}$.

Pesquisa sobre sintomas vocais, realizada com profissionais da voz, revelou que as queixas como rouquidão, dor de garganta, pigarro e ardor na garganta seriam causa, na opinião dos participantes, dos problemas de saúde, do uso profissional e intenso da voz, do stress e da poluição ${ }^{21}$.

Apontou-se que a falta de orientações de profissionais especializados pode vir a acarretar danos à saúde vocal do indivíduo que faz uso da voz para o canto. Em casos mais graves, pode haver episódios de rouquidão de grau moderado após uma apresentação ${ }^{33}$.

A literatura também refere que o pigarro está relacionado ao aumento da viscosidade do muco da região laríngea, sendo considerado indicador de falta de hidratação, higiene vocal pobre e um dos fatores de maior abuso vocal, enfatizando-se que os cantores evitem ao máximo esse hábito ${ }^{19}$.

Em um estudo apontou-se relação estatisticamente significante entre o pigarro, o tabagismo e o uso de drogas ${ }^{21}$. No entanto, na presente pesquisa, não se encontrou significância estatística sobre o uso de tabaco ou de drogas.

Os cantores amadores, comparativamente aos cantores profissionais, apresentaram significância estatística para ausência de problemas de voz diagnosticados, ausência de avaliação otorrinolaringológica e ausência de terapia fonoaudiológica.

Estudo sobre a análise perceptivo-auditiva de cantores do estilo de música brega da cidade de Recife ressalta que, muitas vezes, a busca pelo sucesso dos cantores pode relacionar-se à necessidade de melhorar sua condição financeira, à busca pelo reconhecimento do seu talento, e ao desejo de ser conhecido pela mídia. Desta maneira, os cantores presenciam dilemas quanto a escolher seu repertório musical visando à aceitação do público-alvo, bem como manter uma performance no canto que favoreça o seu destaque. No estilo de música popular, como nos demais estilos musicais, há concorrência entre os cantores, sendo comum verificar cantores com sintomas que são prejudiciais à voz após as apresentações ${ }^{33}$.
A categoria amadora em relação à profissional apresentou ausência significante de orientações sobre anatomia e fisiologia da voz.

Noções sobre anatomia e fisiologia da laringe $e$ demais órgãos do trato vocal são importantes para os cantores. Durante o canto popular, a laringe está em constante movimento de elevação e abaixamento que possibilita as inflexões de graves e agudos da voz falada presentes nesse estilo musical. É importante o cantor saber as consequências negativas de manter a laringe em posição fixa ${ }^{12}$.

Já os profissionais, quando comparados aos cantores amadores, apresentaram conhecimento significante sobre articulação. A articulação precisa é sinal de domínio fonoarticulatório e é importante para a adequada compreensão da palavra que se quer transmitir. Em ambientes maiores, a associação de adequada articulação à boa projeção é fundamental para o alcance vocal ${ }^{31}$.

Em estudo sobre cantores do estilo brega, verificou-se que a voz bem projetada e a articulação precisa foram características encontradas em, respectivamente, $76,9 \%$ e $100 \%$ dos cantores, sendo recursos positivos para a voz cantada ${ }^{33}$.

Quanto ao uso de agentes prejudiciais à voz, observou-se estatisticamente que o uso de álcool durante os ensaios não é hábito entre os cantores amadores, quando comparados aos profissionais. Entretanto, na categoria profissional, o uso de bebidas alcoólicas durante os shows foi significante comparativamente aos amadores.

A literatura afirma que hábitos inadequados de natureza externa (tabagismo, etilismo e a presença ou exposição ao ar condicionado) e do próprio comportamento vocal (fonotrauma por abuso ou mau uso vocal) são comuns entre a população ${ }^{17,21}$.

É importante mostrar ao profissional da voz cantada que alguns hábitos podem prejudicar seu precioso instrumento de trabalho. Pesquisa sobre a correlação entre comprimento de prega vocal e classificação da voz de cantores mostrou que fatores como idade, condições sócio culturais, saúde geral (alterações hormonais, endócrinas, psicológicas, problemas em vias áreas superiores e inferiores, entre outros), hábitos relacionados à saúde vocal (fumo, álcool, alimentação, hidratação etc.) influenciam a classificação vocal ${ }^{35}$.

Sabe-se que a classificação das vozes é importante e constitui-se em um desafio para os profissionais que trabalham com os cantores. Além do médico, responsável pela avaliação otorrinolaringológica, verifica-se a atuação de outros profissionais como preparadores de canto, regentes, professores e fonoaudiólogos ${ }^{12} \mathrm{e}$, em presença de fatores agressivos ao trato vocal como é o álcool, 
a classificação correta pode ficar comprometida, prejudicando também o desempenho e a saúde do cantor.

O profissional da voz geralmente mantém grande demanda vocal por longos períodos, sendo que esta sobrecarga ao aparelho fonador poderá levar à sensação de fadiga vocal. Para amenizar tal sintoma, alguns profissionais, principalmente os cantores, possuem o hábito de ingerir bebidas alcoólicas para "soltar a voz" e proporcionar maior uso vocal durante os shows ${ }^{13}$.

$\mathrm{Na}$ categoria amadora, comparada à categoria profissional, houve significância para a ausência do uso de álcool, possivelmente por este cantor não apresentar grande demanda vocal, uma vez que suas apresentações são esporádicas e sem tanta pressão de público, empresário, contratos, etc.

Além disso, os cantores amadores entrevistados, quando comparados aos cantores profissionais, significantemente não realizam terapia fonoaudiológica.

Entre os profissionais da voz, é comum encontrar aqueles que nunca procuraram auxílio específico e, no caso dos cantores, nunca terem feito aulas de canto ou mesmo uma terapia fonoaudiológica. A prática do canto, mesmo não profissional, quando aliada a técnicas adequadas, pode promover o aumento da extensão vocal, servindo como exercício para a longevidade vocal, amenizando os efeitos negativos que ocorrem no decorrer da vida. Desta maneira, o cantor sob treinamento vocal provavelmente terá benefícios para a sua saúde vocal, prorrogando sua carreira profissional ${ }^{12}$.

O conhecimento do histórico, dos hábitos e dos comportamentos vocais de profissionais da voz como os cantores populares é importante, pois direciona o trabalho fonoaudiológico quanto à conscientização e orientações sobre os cuidados com a saúde vocal e conseqüente longevidade da voz. Neste estudo, investigou-se um grupo de cantores do estilo popular, sendo que as diferenças entre homens e mulheres e entre amadores e profissionais foram evidentes. Desta forma, o fonoaudiólogo, conhecendo melhor o perfil vocal do cantor, poderá contribuir para um desempenho melhor.

\section{CONCLUSÃO}

Dentre o grupo de cantores populares entrevistados neste estudo, verificou-se que os cantores do sexo masculino, quando comparados às cantoras, utilizavam microfone no ensaio, não apresentavam problemas alérgicos ou respiratórios e não apresentavam problemas de voz diagnosticados, mas apresentavam sensação de dor ou desconforto após o canto e não possuíam noções sobre higiene vocal. As cantoras, quando comparadas ao grupo composto por homens, realizavam aulas de canto e possuíam orientações de postura.

Os cantores amadores, comparados ao grupo de cantores profissionais, não cantavam dançando, não imitavam vozes, não utilizavam álcool durante os ensaios, e não apresentavam problemas de voz diagnosticados, mas não possuíam avaliação otorrinolaringológica, não realizavam terapia fonoaudiológica, e não possuíam conhecimento sobre anatomofisiologia vocal. A categoria profissional, quando comparada à categoria amadora, apresentava queixa de rouquidão, de "garganta suja" ou pigarro e de dor após cantar, e usava álcool durante os shows, apesar de possuir conhecimento sobre articulação. 


\begin{abstract}
Purpose: to investigate aspects of vocal history, vocal habits and vocal behavior of popular singers, according to gender and professional and amateur categories. Method: interview with 47 singers, 25 men and 22 women. Results: there were statistical significance differences in the following findings: MALE - microphone during rehearsal, absence of diagnosed voice problems, lack of assistance on vocal hygiene, pain or discomfort after singing, but no allergies or respiratory problems; FEMALES singing lessons and awareness of posture; AMATEUR - no dancing while singing, no imitating voices, lack of otolaryngological evaluation (ENT), no diagnosed vocal problems, lack of speech-language therapy, absence of guidelines on vocal anatomy/physiology and without alcohol consumption during the rehearsals; PROFESSIONAL- hoarseness, knowledge about articulation, alcohol consumption during performance, excess throat clearing, pain after singing. Conclusions: the comparison between genders showed male singers were using microphone in rehearsals, did not have respiratory or allergic problems, nor voice problems were diagnosed, but they had pain sensation or discomfort after singing and did not have vocal hygiene, and female singers had singing lessons and followed posture guidelines. The comparison between amateurs and professionals showed that amateur singers did not dance while singing, did not imitate voices, did not consume alcohol during rehearsals, and did not have diagnosed voice problems, but they did not have ENT evaluation, nor did they engage in speechlanguage therapy, and had no awareness of vocal anatomy/physiology; and the professional singers complained of hoarseness, excess throat clearing and pain after singing, and they consumed alcohol during singing, despite having knowledge about articulation.
\end{abstract}

KEYWORDS: Voice; Voice Quality; Speech, Language and Hearing Sciences; Music; Health Profile; Voice Disorders

\section{REFERÊNCIAS}

1. Costa HO, Silva MAA. Voz cantada: evolução, avaliação e terapia fonoaudiológica. 1 ed. São Paulo: Editora Lovise, 1998. 181 p.

2. Camargo TF, Barbosa DA, Teles, LCS. Características da fonetografia em coristas de diferentes classificações vocais. Rev Soc Bras Fonoaudiol. 2007; 12(1):10-7.

3. Watts C, Murphy J, Barnes-Burroughs K. Pitch matching accuracy of trained singers, untrained subjects with talented singing voices, and untrained subjects with nontalented singing voices in conditions of varying feedback. J Voice. 2003; 17(2):185-94.

4. Estis JM, Coblentz JK, Moore RE. Effects of increasing time delays on pitch-matching accuracy in trained singers and untrained individuals. J Voice. 2009; 23(4): 439-45.

5. Mifune E, Justino VSS, Camargo, Z; Gregio, F. Análise acústica da voz do idoso: caracterização da frequência fundamental. Rev CEFAC. 2007; 9(2): 238-47.

6. Dinville C. A Técnica da voz cantada. Tradução da 2 ed. Rio de Janeiro: Enelivros, 1993. 142 p.

7. Amato RCF. Investigação sobre o fluxo expiratório na emissão cantada e falada de vogais do português em cantores líricos brasileiros. Rev Musica Hodie. 2007;7(1): 67-82.

8. Pettersen V, Bjorkoy K. Consequences from emotional stimulus on breathing for singing. J Voice. 2009; 23(3): 295-303

9. Behlau MS, Feijó D, Madazio G, Rehder MI, Azevedo R, Ferreira AE. Voz profissional: aspectos gerais e atuação fonoaudiológica. In: Behlau MS. Voz: o livro do especialista. v. II. Rio de Janeiro: Revinter; 2005. p.287-406.

10. Braga A, Pederiva P. Voz e corporeidade segundo a percepção de coristas. Rev Musica Hodie. 2007; 7(2):43-51.

11. Gampel D. Aspectos de intervenção fonoaudiológica em apresentadores de previsão meteorológica sem problemas vocais. Rev Dist Comun. 2006; 18(3): 355-69.

12. Costa PJBM, Ferreira $\mathrm{KL}$, Camargo ZA, Pinho SMR. Extensão vocal de cantores de coros evangélicos amadores. Rev CEFAC. 2006; 8(1): 96-106.

13. Pinho SMR. Manual de higiene vocal para profissionais da voz. Carapicuíba: Pró-fono, 2007. 34p.

14. Ueda KH, Santos LZ, Oliveira IB. 25 anos de cuidados com a voz profissional: avaliando ações. Rev CEFAC. 2008; 10(4): 557-65. 
15. Fortes FSG, Imamura R, Tsuji DH, Sennes LU. Perfil dos profissionais da voz com queixas vocais atendidos em um centro terciário de saúde. Rev Bras Otorrinolaringol. 2007; 73(1): 27-31.

16. Rocha TF, Amaral FP, Hanayama EM. Extensão vocal de idosos coralistas e não coralistas. Rev CEFAC. 2007; 9(2):248-54.

17. Behlau MS, Azevedo R, Pontes P. Conceito de voz normal e classificação das disfonias. In: Behlau M. Voz: o livro do especialista. Rio de Janeiro: Revinter; 2008. p. 53-84.

18. Amato RCF, Carlini MM. A saúde vocal dos educadores musicais: um estudo comparativo com docentes atuantes na educação infantil e no ensino fundamental. Rev Musica Hodie. 2008; 8(2): 107-25. 19. Rehder MIBC, Behlau MS. Perfil vocal de regentes de coral do estado de São Paulo. Rev CEFAC. 2008; 10(2): 206-17.

20. Ferreira LP, Luciano P, Akutsu CM. Condições de produção vocal de vendedores de móveis e eletrodomésticos: correlação entre questões de saúde, hábitos e sintomas vocais. Rev CEFAC. 2008; 10(4):528-35.

21. Ferreira LP, Santos JG, Lima MFB. Sintoma vocal e sua provável causa: levantamento de dados em uma população. Rev CEFAC. 2009; 11(1):110-8. 22. Ferreira LP, Benedetti, PH. Condições de produção vocal de professores de deficientes auditivos. Rev CEFAC. 2007; 9(1):79-89.

23. Mendes AP, Brown WSJR, Rothman HB, Sapienza C. Effects of singing training on the speaking voice of voice majors. J Voice. 2004; 18(1):83-9.

24. Watts C, Barnes-Burroughs K, Estis J, Blanton $D$. The singing power ratio as an objective measure of singing voice quality in untrained talented and nontalented singers. J Voice. 2006; 20(1): 82-8.

25. Laukkanen AM, Lindholm P, Vilkman E. On the effects of various vocal training methods on glottal resistance and efficiency: a preliminary report. Folia Phoniatr Logop. 1995; 47(6):324-30.
26. Mello EL, Silva MAA. O corpo do cantor: alongar, relaxar ou aquecer? Rev CEFAC, São Paulo: 2008: 10(4): 548-56.

27. Tavares JG, Silva EHAA. Considerações teóricas sobre a relação entre respiração oral e disfonia. Rev Soc Bras Fonoaudiol. 2008: 13(4):405-10.

28. Soares EB, Borba DT, Barbosa TKM, Montenegro ACA. Hábitos vocais em dois grupos de idosos. Rev CEFAC. 2007; 9(2): 221-7.

29. Cielo CA, Finger LS, Roman-Niehues G, Deuschle VP, Siqueira MA. Disfonia organofuncional e queixas de distúrbios alérgicos e/ou digestivos. Rev CEFAC. 2009; 11(3): 431-9.

30. Roman G, Cielo CA. Particularidades da técnica fonoterapêutica de sons hiperagudos: revisão de literatura. Rev CEFAC. 2006; 8(3):360-7.

31. Souza DPD, Silva APBV, Jarrus ME, Pinho SMR. Avaliação fonoaudiológica vocal em cantores infanto-juvenis. Rev CEFAC. 2006; 8(2): 216-22.

32. Silverio KCA, Gonçalves CGO, Penteado RZ, Vieira TPG, Libardi A, Rossi D. Ações em saúde vocal: proposta de melhoria do perfi I vocal de professores. Pró-Fono. 2008; 20(3):177-82.

33. Silva EGF, Luna CLC. Análise perceptivoauditiva de parâmetros vocais em cantores da noite do estilo musical brega da cidade do Recife. Rev CEFAC 2009; 11(3):457-64.

34. Nemr K, Amar A, Abrahäo M, Leite GCA, Köhle JS, Santos AO, Correa, LAC. Análise comparativa entre avaliação fonoaudiológica perceptivo-auditiva, análise acústica e laringoscopias indiretas para avaliação vocal em população com queixa vocal. Rev Bras Otorrinolaringol. 2005; 71(1):13-7.

35. Mello EL, Silva MA. Correlação entre comprimento de prega vocal e classificação da voz de cantores: um estudo de medidas morfológicas por meio de raios X. Rev Soc Bras Fonoaudiol. 2010; 15(2):307-8.
http://dx.doi.org/10.1590/S1516-18462011005000101

RECEBIDO EM: 07/12/2010

ACEITO EM: 24/04/2011

Endereço para correspondência:

Carla Aparecida Cielo

Rua Pedro Londero, 155 - Santa Maria - RS

CEP: $97095-530$

E-mail: cieloca@yahoo.com.br 